\author{
Justyna Kobus \\ Uniwersytet im. Adama Mickiewicza w Poznaniu \\ Instytut Filologii Polskiej \\ ORCID: 0000-0002-4094-2743; e-mail: jusper@amu.edu.pl
}

\title{
Wialnia i młynek w języku mieszkańców wybranych wsi wielkopolskich
}

\begin{abstract}
Abstrakt: W artykule podjęto problem relacji nazwa-desygnat na przykładzie nazw maszyn do czyszczenia oraz sortowania zboża. Analizy opierają się głównie na materiale wielkopolskim z odwołaniami do źródeł z innych regionów. Pozyskane współcześnie dane terenowe zostały zestawione z danymi Atlasu języka $i$ kultury ludowej Wielkopolski, co pozwoliło wykazać zmiany zachodzące w zakresie badanych nazw.
\end{abstract}

Słowa kluczowe: gwara, język mieszkańców wsi, nazwa, desygnat

\begin{abstract}
Wialnia and mlynek in the language of the inhabitants of selected Greater Poland villages. The article discusses the name-designate relation by resorting to the example of names of machines: aerial separator and grain sorter. The analyses are based mainly on material collected in Greater Poland with reference to sources from other regions. The recently collated field data are juxtaposed with data from Atlas języka i kultury ludowej Wielkopolski (Atlas of Great Poland's language and folk culture) which made it possible to demonstrate changes in the names in question.
\end{abstract}

Keywords: dialect, language of the villagers, name, designate

Studia dialektologiczne - już od początków istnienia tej gałęzi językoznawstwa - są ściśle związane z etnografią; jest to oczywisty fakt, który coraz częściej o sobie przypomina podczas prac terenowych. Szczególne znaczenie etnografii ujawnia się w trakcie badania dotyczącego rzeczy i czynności wychodzących z użycia. Współcześnie informatorzy udzielają coraz mniej precyzyjnych odpowiedzi, z większą częstotliwością można też zauważyć brak rozróżnienia nazwy i odpowiadającego jej desygnatu. W świetle takich obserwacji niezwykłej wagi nabiera szczegółowa znajomość badanego tematu.

W artykule zaprezentuję dwie dawne maszyny o zróżnicowanym zastosowaniu, których nazwy często stosowane są wymiennie. Mam na myśli maszynę do oczyszczania ziarna $\mathrm{z}$ plew oraz maszynę do segregacji ziarna na pełnowartościowe i gorsze (tzw. poślad). Chodzi o nazwy z pola tematycznego PRACA, konkretnie zaś o leksemy wialnia/wiejnia oraz młynek. Ich funkcjonowanie jest o tyle interesujące, że często stosowane są na określenie tego samego typu maszyny, innym razem wyraźnie różnicują nazywane desygnaty. 
Dotychczas wspomniane maszyny nie były przedmiotem szczegółowych badań. Zwykle dialektolodzy pytali o jedną z nich (najczęściej o maszynę do czyszczenia ziarna z plew). Wyniki badań można znaleźć m.in. W Atlasie językowym Ślaska (dalej: AJS), Atlasie języka i kultury ludowej Wielkopolski (dalej: AJKLW), Atlasie gwar Mazowieckich (dalej: AGM); informacje na ten temat można także wyszukać w niektórych słownikach gwarowych, np. Mały słownik gwar polskich (Wronicz 2010), Stownik gwary orawskiej (Kąś 2011), Słownik gwar Lubelszczyzny... (Pelcowa 2012), Słownik języka mieszkańców ziemi łukowskiej (Sierociuk 2019) czy w niektórych monografiach (np. Irminy Judyckiej [1961]). Większość wymienionych opracowań nie dotyczy jednak materiału najnowszego, ani też nie przedstawia uwikłania interesujących nas nazw i desygnatów w oddziaływania pozajęzykowe.

Przywoływany przeze mnie najnowszy wielkopolski materiał (zob. tabela 2) pochodzi z kilku wsi regionu, wśród których punktami głównymi są 4 miejscowości, mianowicie: Adamów (gm. Golina, pow. Konin) ${ }^{1}$ - wschodnia Wielkopolska, Baranówko i Sowinki (gm. Mosina, pow. Poznań, traktowane jako 1 punk badawczy) ${ }^{2}$ - środkowa Wielkopolska, Bukówiec Górny (gm. Włoszakowice, pow. Leszno, punkt 74 AJKLW) ${ }^{3}$ - południowa Wielkopolska, Dąbrówka Wielkopolska (gm. Zbąszynek, pow. Świebodzin, punkt 45 AJKLW) ${ }^{4}$ - zachodnia część regionu. Materiał z punktów głównych w miarę możliwości uzupełniam danymi pozyskanymi w innych wsiach, głównie przy okazji eksploracji do gwarowych projektów edukacyjnych, zatem z okolic Czerniejewa W powiecie gnieźnieńskim (zob. Kobus, Stępień 2018) i z powiatu kolskiego (zob. Osowski 2018). Analizy prowadzę zgodnie z zasadą przyjętą w Pracowni Dialektologicznej UAM.

Materiały gwarowe dostarczają poświadczeń, które - po głębszej analizie - trudno jest uporządkować. Myślę tu nie tylko o współczesnych danych wielkopolskich, ale ogólnie o dostępnych źródłach dialektologicznych. W Małym słowniku gwar polskich odnotowane zostały dwie nazwy o zbliżonym (praktycznie zaś tym samym) znaczeniu: młynek 'maszyna do czyszczenia ziarna; wialnia' oraz wiejnia 'maszyna do czyszczenia zboża'. Obydwie nazwy zostały poświadczone (obok Mazowsza i Małopolski) w Wielkopolsce, przy czym druga z nich - wiejnia - wystąpiła w Kramsku koło Konina, Wielkopolska południowo-wschodnia; przy młynku podano ogólnie Wielkopolskę. Obok AJKLW, AJS mapuje nazwy 'młynka do wiania zboża' (m. 133, t. II). Problematykę związaną z tym zagadnieniem porusza także AGM, w którym znajdziemy mapę 175 'sita w wialni' (t. IV). Pozostałe dzieła atlasowe nie podjęły tematu eksplorowanego w tym artykule.

Ciekawostką mogą być zapisy, które odnaleźć można w monografii I. Judyckiej. Badaczka przywołuje cztery nazwy wariantywne, tj. wialnia, wiewalnia, wiewka, wiew-

\footnotetext{
1 Informatorzy: MaZ - kobieta ur. 1941, PuB - mężczyzna ur. 1942, PuA - kobieta ur. 1947, KuW mężczyzna ur. 1952.

2 Informatorzy: MiZ - mężczyzna ur. 1926, RaA - mężczyzna ur. 1931, MiJ - mężczyzna ur. 1964, MiG - kobieta ur. 1966.

3 Informatorzy: SoW - kobieta ur. 1920, SzJ - mężczyzna ur. 1925, MłP - kobieta ur. 1929, BaK kobieta ur. 1947, MaM - kobieta ur. 1948, MaH -mężczyzna ur. 1955, WoS - mężczyzna ur. 1959, WoM - kobieta ur. 1959.

4 Informatorzy: NiA - kobieta ur. 1924, NiŁ - kobieta ur. 1929, DuM - kobieta ur. 1929, GoS - mężczyzna ur. 1939, DuR - kobieta ur. 1955, WiW - mężczyzna ur. 1955, SeZ - mężczyzna ur. 1962.
} 
nik oraz nazwę 'młynka do czyszczenia ziarna' - wiatrówka. Nieco inna definicja, zawierająca określenie mlynek, sugeruje, że trzy pozostałe urządzenia odróżniają się od owej wiatrówki. Trudno jednak wychwycić ewentualne różnice semantyczne z uwagi na brak jakichkolwiek kontekstów czy dodatkowych opisów dla tych przykładów.

Interesującym kontekstem dla naszych rozważań są dane ze słowników J. Kąsia, J. Sierociuka i H. Pelcowej, dotyczące odpowiednio gwary orawskiej oraz gwary okolic Łukowa, jak i ogólnie Lubelszczyzny. I tak na Orawie zanotowano nazwy maszyny służącej do oddzielania ziarna od plew: wiejacka '2. maszyna do wiania zboża, napędzana ręcznie', wiejak/wiejaki to samo co WIEJACKA w zn. 2, mlynek/mlynki to samo co WIEJACKA w zn. 2, trzepaki to samo co WIEJACKA w zn. 2. Z kolei w gwarach lubelskich H. Pelcowa wymienia następujące nazwy 'maszyny do oczyszczania zboża, oddzielania ziarna od plew': buczek, mlyneczek polski, mlynek, wialnia, wialnica, wiej$k a$, wijatka, żmijka. Zaś w okolicach Łukowa J. Sierociuk współcześnie odnotował wialnię, trenek i mlynek jako nazwy 'maszyny do czyszczenia (wiania) zboża'.

W dziełach tak wielu badaczy nie spotyka się rozgraniczenia na maszynę służącą do oczyszczania ziarna zbóż z plew i nasion chwastów oraz na taką, która ziarno segreguje na lepsze, nadające się do siewu i gorsze, przeznaczone na paszę. Inaczej niż jest to we współczesnych badaniach wielkopolskich, w których sytuacja taka nie jest rzadkością. Co więcej, w słowniku H. Pelcowej umieszczona została ilustracja 35 przedstawiająca opisywany desygnat, który w Wielkopolsce także jest maszyną do oczyszczania ziarna z plew, ale nazwa jest związana ze sposobem pracy tegoż urządzenia $-\mathrm{z}$ wianiem (wykorzystywanie podmuchu).

Zanim przejdę do analizy współczesnych danych wielkopolskich, sprawdzę, jakie nazwy można znaleźć w AJKLW dla współcześnie badanych punktów lub ich okolicy. W AJKLW nazwy badanego desygnatu zostały przedstawione na m. 305 i 306 (zob. AJKLW-II), i dotyczą nazw maszyny wykorzystywanej do czyszczenia zboża. Nie ma w atlasie mapy dla nazw maszyny, której używano do przesortowania ziaren. Ponadto w AJKLW-II zawarto szczegółowy podział tychże maszyn w zależności od liczby sit (zob. tabela 1.).

Jak wynika $\mathrm{z}$ wyekscerpowanego materiału już zespół AJKLW zanotował pewne rozbieżności podkreślające różnice między maszynami, ale i wariantywność nazewniczą. W punkcie 45 natomiast nazwy obydwu maszyn są identyczne.

Porównajmy te dane ze współcześnie pozyskanymi poświadczeniami (zob. tabela 2.). We współczesnych badaniach pytano o 'maszynę do czyszczenia ziarna z plew' oraz o 'maszynę do sortowania ziarna'.

Na podstawie wyselekcjonowanego materiału zaobserwować można kilka problemów. Po pierwsze, dane nie stanowią zbyt obszernego zbioru nazw, co w połączeniu z reakcją informatorów na konkretne pytania pozwala wnioskować m.in. o braku ich wiedzy na temat obydwu desygnatów i ich nazw zwłaszcza w pokoleniu III; niektóre odpowiedzi sugerują, że informatorzy nie rozróżniają obydwu przedmiotów albo też nie funkcjonowały one $\mathrm{w}$ ich gospodarstwie (może nawet wsi).

Najbardziej przejrzystą sytuację widać w Adamowie. Tu precyzyjnie rozkłada się podział na desygnaty $\mathrm{i}$ ich odrębne nazwy - mamy więc odpowiednio wiejnię do czyszczenia ziarna z plew oraz mlynek segregujący ziarno na lepsze i gorsze. Sytuacja taka powtarza się w obydwu zbadanych pokoleniach. 
Tabela 1. Nazwy 'maszyny do czyszczenia ziarna bez sit lub z jednym sitem' (m. 305) i 'maszyny do czyszczenia ziarna z sitami' (m. 306) - AJKLW.

\begin{tabular}{|c|c|c|}
\hline Punkt & $\begin{array}{c}\text { 'Maszyna do czyszczenia ziarna } \\
\text { bez sit lub z jednym sitem' } \\
(\mathrm{m} .305)\end{array}$ & $\begin{array}{c}\text { 'Maszyna do czyszczenia ziarna } \\
\text { z sitami' (m. 306) }\end{array}$ \\
\hline 56, 56a - okolice Adamowa & wialnia & wiejnia \\
\hline $\begin{array}{c}50,51 \text { - okolice Baranówka } \\
\text { i Sowinek }\end{array}$ & wietrznik & $\begin{array}{c}\text { wiewnik, wialnia, mtynek, } \\
\text { wiejnia }\end{array}$ \\
\hline 74 - Bukówiec G. & czyszczarka & mtynek \\
\hline 45 - Dąbrówka Wlkp. & mlynek & mtynek \\
\hline
\end{tabular}

Tabela 2. Nazwy 'maszyny do czyszczenia ziarna' i 'maszyny do sortowania ziarna' w materiałach współczesnych.

\begin{tabular}{|c|c|c|c|c|c|}
\hline \multirow{2}{*}{ Miejscowość } & \multicolumn{3}{|c|}{ 'Maszyna do czyszczenia ziarna z plew' } & \multicolumn{2}{|c|}{ 'Maszyna do sortowania ziarna' } \\
\hline & p. I & p. II & p. III & p. II & p. III \\
\hline Adamów & - & $\begin{array}{c}\text { wiejnia } \\
\mathrm{MaZ}, \mathbf{P u B}\end{array}$ & $\begin{array}{c}\text { wiejnia } \\
\mathrm{PuA}, \mathbf{K u W}\end{array}$ & $\begin{array}{c}\text { mtynek } \\
\text { PuB }\end{array}$ & $\begin{array}{c}\text { mtynek } \\
\mathbf{K u W}\end{array}$ \\
\hline $\begin{array}{l}\text { Baranówko } \\
\text { i Sowinki }\end{array}$ & - & $\begin{array}{c}\text { wialnia } \\
\text { MiZ, RaA } \\
\text { czyszczarka } \\
\text { MiZ, RaA } \\
\text { czyszczalnia } \\
\text { RaA }\end{array}$ & $\begin{array}{l}\text { wialnia } \\
\text { MiJ, MiG }\end{array}$ & - & $\begin{array}{c}\text { wialnia } \\
\mathbf{M i G}\end{array}$ \\
\hline Bukówiec G. & $\begin{array}{c}\text { mtynek } \\
\text { SoW }\end{array}$ & $\begin{array}{c}\text { mtynek } \\
\text { MłP, SzJ } \\
\text { wie wnik MłP } \\
\text { wialnia / } \\
\text { wiolnia } \text { SzJ } \\
\text { (bierne) }\end{array}$ & $\begin{array}{c}\text { mtynek } \\
\text { BaK, WoS, } \\
\text { MaH, MaM } \\
\text { wiewnik WoS } \\
\text { czyszczarka } \\
\text { WoS }\end{array}$ & $\begin{array}{c}\text { mtynek SzJ } \\
\text { mnijszy mtynek } \\
\text { SzJ } \\
\text { wiewnik MłP }\end{array}$ & $\begin{array}{c}\text { maty mtynek } \\
\text { BaK, WoS, } \\
\text { WoM, MaM } \\
\text { mtyneczek BaK }\end{array}$ \\
\hline $\begin{array}{l}\text { Dąbrówka } \\
\text { Wlkp. }\end{array}$ & - & $\begin{array}{c}\text { mbynek } \\
\text { DuM, NiŁ } \\
\text { wialnia GoS } \\
\text { mbynec (!) NiA }\end{array}$ & $\begin{array}{c}\text { mtynek } \\
\text { SeZ }\end{array}$ & $\begin{array}{c}\text { mtynek } \\
\text { DuM, GoS } \\
\text { mbynek } \\
\text { wiatrowy } \mathbf{G o S}\end{array}$ & klaper [DuR] \\
\hline
\end{tabular}




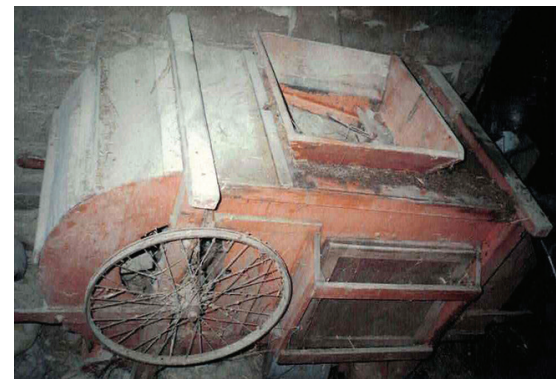

Fot. 1. Wialnia - Baranówko 2005 r. (fot. J. Kobus)

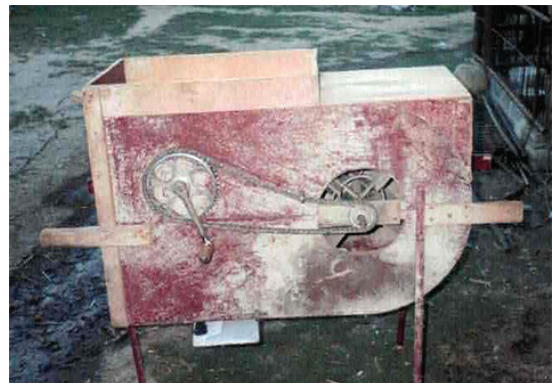

Fot. 2. Młynek - Adamów 2005 r. (fot. J. Kobus)

W Baranówku i Sowinkach nie udało się potwierdzić używania 'maszyny do segregacji ziarna', a jedynie uzyskano poświadczenie dla 'maszyny do czyszczenia ziarna' - wialnia, czyszczarka, czyszczalnia; tylko najmłodsza informatorka wymieniła tę samą nazwę w odpowiedzi na pytanie o dwa różne urządzenia, co może być wynikiem jej wewnętrznego przekonania o konieczności udzielenia odpowiedzi, niekoniecznie zaś jej znajomości. W punkcie tym w pokoleniu II została także odnotowana nazwa $c z y s z-$ czarka/czyszczalnia - dotyczy ona jednak innego rodzaju maszyny, bardziej zaawansowanej pod względem technologicznym, która młóci i jednocześnie oczyszcza ziarno z plew:

MiZ: czyszczarka to jezd maszyna od... która młóci i zaraz czyści... a to maszyny które kiedyź myśmy mieli to trzeba było jeszcze... bo tam zboże sie tylko wykruszyło... a trzeba było późni na wialnie... [...] za pomoco ${ }^{m}$ takich śmig... no oczywiście przekaźnik byt... tryby żelazne... nie... i śmigi na tym byly osadzone... a w końcu ruchome takie byto na takich takie wah... tak wahadtowo chodzity cztery sita $i$ one to... to ziarno tam splywało... zlatywało... wiatr wydmuchiwat bo tu przy tym... przy tych kolbie byty takie śmigi... $i$ te wydmuchiwaty... wydmuchywaty (!) tam te plewe a ziarno... a sita byty po to że nawed one... oddzielaty te drobniejsze ziarno grubsze $i \ldots i$... i na dole było takie przez które przelatywaty te wszystkie chwasty... te nasiona chwastów... tak...

W Bukówcu G. pojedynczo odnotowano nazwę czyszczarka, zgodną z notacją AJKLW (tu dziwi, że nazwa ta padła w pokoleniu III, a nie w II, co może sugerować, że informator miał na myśli nieco nowsze urządzenie, niż to, o które pytano). Pozostałe nazwy cechuje stosunkowo wysoka różnorodność, ponieważ występuje tu aż 7 wariantów. Informatorzy z Bukówca G. na pytanie o 'maszynę do czyszczenia ziarna' udzielili następujących odpowiedzi: młynek (p. I), młynek, wi wnik i wialnia (p. II) i mtynek, wiewnik (p. III), natomiast na 'maszynę do segregacji ziarna' mówią: młynek, mniejszy młynek, wi wnik (p. II) oraz mały młynek, młyneczek (p. III). Rozróżnienie obydwu urządzeń sprowadza się do parametru rozmiaru (mały, mniejszy) oraz sposobu działania wiewnik/wiewnik i wialnia od wiania, działania za pomoca podmuchu, wywiewania lekkich plew i najsłabszych ziaren pośladu. Współcześni mieszkańcy wsi nie uwzględniają typowego niegdyś wyznacznika, jakim była budowa tego rodzaju maszyn, mianowicie obecności sit - co stanowiło punkt wyjścia dla zespołu AJKLW, mapującego 
nazwy 'maszyny do czyszczenia zboża bez sit lub z jednym sitem' (m. 305) i 'maszyny do czyszczenia zboża z sitami’ (m. 306).

Dąbrowszczanie wymieniają dość jednolity zestaw nazw, które w pokoleniu II są częściowo jednakowe dla obydwu interesujących nas maszyn - młynek. Wyłącznie nazwy maszyny czyszczącej ziarno, w pokoleniu II, są urozmaicone o dwie dodatkowe: wialnia, młynec oraz w pokoleniu III klaper jako nazwa 'maszyny do segregacji ziarna'.

Istotną uwagę stanowi zapis, w którym nazwy obydwu desygnatów były podane przez te same osoby (w tabeli oznaczone pogrubioną czcionką). Na tej podstawie można mówić o występowaniu $\mathrm{w}$ danej wsi dwóch różnych maszyn, pełniących różne funkcje, jak to jest w Adamowie, gdzie ten sam informator podaje różne nazwy określające różne maszyny: wiejnia [PuB, KuW] jako maszyna czyszcząca zboże i młynek $[\mathrm{PuB}, \mathrm{KuW}]$ jako maszyna segregująca zboże. Podobnie jest w wypadku niektórych informatorów z Bukówca G., choć nie dotyczy to wszystkich poświadczeń (mylić mogą te oznaczone gwiazdka): mlynek, wi wnik* MłP i wiewnik* MłP, młynek*/wialnia/wiolnia (bierne) SzJ i mtynek*/mnijszy mtynek SzJ, mtynek BaK i mtyneczek/maty mtynek $\mathrm{BaK}$, młynek/wiewnik/czyszczarka WoS i maty mlynek WoS, mtynek MaM i maty mtynek MaM lub z Dąbrówki Wlkp.: wialnia GoS i mtynek/mtynek wiatrowy GoS.

Należy także uwzględnić sytuację, w której badani informatorzy nie kojarzą dwóch urządzeń bądź we wsi nie było takich sprzętów (jak w Baranówku i Sowinkach, o czym była mowa wyżej). Udzielnie takich samych odpowiedzi na różne pytania jest zastanawiające (wialnia MiG i wialnia MiG, młynek DuM i mtynek DuM) - czy należy to przypisać niewiedzy informatora, czy może daleko idącemu uogólnieniu? Są to przesłanki, które muszą zostać zweryfikowane drogą szczegółowych badań terenowych.

Inną obserwacją dokonaną podczas analizy poszczególnych nazw jest to, że w niektórych wypadkach, zwłaszcza w Dąbrówce Wlkp., między podawaną przez informatorów nazwą maszyny i nazwą czynności przez tę maszynę wykonywanej, często ulega zachwianiu relacja rzecz-czynność, np. młynek ale wioć [DuM] [NiŁ], młynec ale: przewione [NiA] obok mtynek - młynkować [WiW] [NiŁ] - zaobserwowane zjawisko dotyczy osób z pokolenia II. W pozostałych miejscowościach takich odchyleń dotychczas nie zauważyłam, mamy tam następujące zapisy: Bukówiec G. młynek - młynkować [SoW] [MaM] [BaK], Baranówko i Sowinki wialnia - przewiać, odwiać [MiJ] [MiG]; Adamów wiejnia - wiać (wije sie, wieli) [WoS] [PuA].

Co ciekawe, w okolicach Czerniejewa (pow. Gniezno) odnotowano cztery nazwy określające 'dawną maszynę do czyszczenia ziarna z plew': klaper (Graby, gm. Czerniejewo), mlynek (Czerniejewo, Graby), wialnia (Czerniejewo, Graby, Goraniec gm. Czerniejewo), wiejnia (Graby). Z wypowiedzi informatorów wyraźnie wynika, że wszystkie te nazwy stosuje się wymiennie, np.: mtynek... wialnia inacy (!)... mtynek... wialnia... (Czerniejewo), jedni mówio ${ }^{m}$ wiejnia... wialnia ... jedni mlyneg $i$ to tam było to samo... (Graby).

Podobną sytuację obserwuje się w powiecie kolskim. Pozyskano tu następujące poświadczenia dla nazwy 'maszyny do sortowania ziarna na lepsze i gorsze' wialnia (Prucheniec), mtynek (Prucheniec, Sobótka, Nowe Budki): wialnia... albo mtynek... (Prucheniec), no to może być wialnia wzglendnie mtynek... (Sobótka). Wśród nazw 'maszyny do czyszczenia zboża' odnotowano tu wyraz wialnia (Prucheniec i Sobótka) 
oraz wiejnia (Nowe Budki). Z notacji tych trudno jednak wywnioskować, o jaką konkretnie maszynę pytano.

Zestawiając te obserwacje $\mathrm{z}$ wynikami badań $\mathrm{z}$ innych obszarów dialektalnych, nasuwa się wniosek o zlewaniu się nazw i desygantów. Wystarczy sięgnąć do wspomnianego już Słownika gwar Lubelszczyzny i dołączonej do niego mapy o numerze 21. Pokazuje ona występowanie wszystkich wymienionych w słowniku wariantów na terenie Lubelszczyzny. Można by się zastanawiać, czy stosunkowo duża wariantywność w słowniku H. Pelcowej jest wynikiem tych samych zjawisk i mechanizmów, które obserwujemy obecnie w języku mieszkańców wielkopolskich wsi, czy może wynika z bazy materiałowej wykorzystanej w tym słowniku - wszak jej przekrój czasowy jest znaczny, bo sięga od czasów współczesnych do lat 50. XX w., a brakuje przy artykułach hasłowych adnotacji co do okresu, z którego pochodzi dana notacja. Przy tak dużej chronologicznej rozpiętości źródłowej wariantywność może być wynikiem zmian językowo-kulturowych, jakie zaszły w przestrzeni wiejskiej, niekoniecznie zaś odzwierciedlać stan badanych nazw w konkretnym przedziale czasowym. To, że jedna nazwa używana była w latach 50 ., wcale nie oznacza, że jest ona znana współcześnie. Szczególnej wagi nabiera tu zatem aspekt temporalny. W związku z tym trudno jest interpretować materiał ze Slownika gwar Lubelszczyzny pod względem zachodzących przemian językowych, przy czym sam fakt odnotowania nazw interesujących nas w prezentowanym artykule, stanowi jednak cenne źródło.

W kontekście najnowszych badań na Lubelszczyźnie dodam jeszcze, że materiały z okolic Łukowa (Sierociuk 2019) zawierają tylko 3 nazwy: wialnia, trenek i młynek, których znaczenia nie do końca są przejrzyste, a coraz częściej zlewają się w jedno:

wialnia albo mlynek... (NJm, Osn, WPn, WKs, Gąs);

przewiać... we wialni lub w mlynku... (Grz);

to ziarno leciało czyste... z tyj właśnie... $z$ tej... wialni... wialnia... $i$ wialnia była do czyszczenia... i mbynek... (Chr);

to $i$ wialnia tak robita... bo oddzielata plewy od ziarna ... ale leciało też... lepsze $i$ gorsze no to mlynek przeważnie byt... oddzielał... wialnia też oddzielała... (Goł).

W Wielkopolsce, zgromadzone współcześnie dane, dotyczące maszyny sortującej zboże, nie znajdują punktu odniesienia w materiałach AJKLW. Przedstawię natomiast zmiany, jakie zaszły w funkcjonowaniu nazw maszyny czyszczącej zboże.

W AJKLW zmapowane zostały nazwy 'maszyny do czyszczenia zboża' bez sit lub z jednym sitem oraz z sitami - chodziło o mniej i bardziej zaawansowany typ maszyny do oczyszczania zboża. Pierwsza z wymienionych maszyn charakteryzowana jest w sposób następujący przez autorów komentarza: „Zadaniem tej maszyny było wstępne oczyszczenie zboża z plew i lżejszych zanieczyszczeń. Młynek stosowano także w celu dokładniejszego oczyszczenia ziarna przewianego w wialni" (AJKLW-II, 2, 99). Z kolei 'maszyna do czyszczenia zboża z sitami' opisana została dość ogólnie: „Służyły do czyszczenia zboża. Oprócz wiatraka wyposażone były w kilka ruchomych sit" (AJKLW-II, 2, 101). Zatem maszyna określana przez autorów AJKLW jako wialnia jest nowocześniejsza od wcześniej opisanych mlynków. Konfrontacja najnowszych danych z mapą wykazała, że: w Dąbrówce Wlkp. odnotowano w AJKLW nazwę $m t y$ nek, co obok wialni udało się potwierdzić współcześnie; okolice Baranówka i Sowinek 
- tu także dane pokrywają się z wynikami AJKLW, mamy bowiem nazwę wialnia; Bukówiec G. - w AJKLW młynek zaś współcześnie wiewnik/wiewnik i wialnia; Adamów - zarówno w atlasie jak i współcześnie odnotowana nazwa to wiejnia.

Wniosek płynący z poczynionych przeglądów wydaje się być następujący: zacieranie się znaczeń i nazw zbliżonych do siebie desygnatów nie jest cechą obserwowaną wyłącznie w Wielkopolsce. W związku z analizowanymi tu nazwami obydwu maszyn, podobną niejednoznaczność zauważamy chociażby w gwarach Lubelszczyzny.

Przedstawione analizy wyraźnie pokazują zmiany, jakie zaszły w języku mieszkańców wsi na przestrzeni ostatniego 30-40-lecia. Zlewanie się nazw i ich znaczeń jest coraz częściej odnotowywane przy pozyskiwaniu materiałów dotyczących przedmiotów i czynności dawnych lub wychodzących z użycia. Już tak skromny materiał udowadnia, że badania dialektologiczno-etnograficzne są konieczne i potrzebne, by w pełni zrozumieć zachodzące zmiany językowe i kulturowe. Zarazem ekscerpcja materiałów gwarowych zmusza do refleksji nad metodami pozyskiwania ich w terenie.

\section{Literatura}

AGM, H. Horodyska-Gadkowska, A. Strzyżewska-Zaremba, Atlas gwar mazowieckich, t. I, Wrocław 1971; A. Kowalska, A. Strzyżewska-Zaremba, Atlas gwar mazowieckich, t. II-X, Wrocław 1972-1992.

AJKLW, Atlas języka i kultury ludowej Wielkopolski, t. I-VI, pod red. Z. Sobierajskiego, J. Burszty, Wrocław [i in.] 1979-1991; t. VII-XI, pod red. Z. Sobierajskiego, Wrocław [i in.] Poznań 1992-2005.

AJKLW-II, Atlas języka i kultury ludowej Wielkopolski, t. II: CZŁOWIEK - PRZYRODA, pod red. Z. Sobierajskiego, J. Burszty, cz. 1: Mapy 116-235, cz. 2: Wykazy i komentarze do map 116-235, Wrocław [i in.] 1979.

AJS, A. Zaręba, Atlas językowy Śląska, t. I, Kraków 1969, t. II, Kraków-Warszawa 1970-1989, t. VIII, Warszawa 1996.

Judycka I. (1961), Stownictwo z zakresu uprawy roli w gwarach Pomorza Mazowieckiego (stan obecny, historia i związi z terenami przyległymi), Wrocław-Warszawa-Kraków 1961.

Kąś J., Stownik gwary orawskiej, t. I-II, Kraków.

Kobus J., Stępień M. (red.) (2018), Słownik języka mieszkańców okolic Czerniejewa. Praca na roli $i$ w gospodarstwie, Poznań.

Osowski B. (red.) (2018), Gospodarz. Słownik języka mieszkańców powiatu kolskiego, Poznań.

Pelcowa H. (2012), Stownik gwar Lubelszczyzny, t. I: Rolnictwo, narzędzia rolnicze, prace polowe, zbiór i obróbka zbóż, Lublin.

Sierociuk J. (2019), Słownik języka mieszkańców ziemi łukowskiej. Praca na roli $i$ w gospodarstwie, Poznań.

Wronicz J. (red.) (2010), Mały słownik gwar polskich, Kraków. 